\title{
Presence of six different lesion types suggests diverse mechanisms of tissue injury in neuromyelitis optica
}

\author{
Tatsuro Misu • Romana Höftberger • Kazuo Fujihara • Isabella Wimmer • \\ Yoshiki Takai · Shuhei Nishiyama • Ichiro Nakashima · Hidehiko Konno • \\ Monika Bradl • Ferenc Garzuly • Yasuto Itoyama · Masashi Aoki • Hans Lassmann
}

Received: 18 February 2013 / Revised: 27 March 2013 / Accepted: 2 April 2013 / Published online: 12 April 2013

(C) The Author(s) 2013. This article is published with open access at Springerlink.com

\begin{abstract}
Neuromyelitis optica (NMO) is an autoimmune disease targeting aquaporin 4 (AQP4), localized mainly at the astrocytic foot processes. Loss of AQP4 and glial fibrillary acidic protein (GFAP) was reported, but the pathological significance of astrocytopathy is still controversial. Here we show that active lesions in NMO display a wide spectrum of pathology even within a single tissue block of an individual patient. We have distinguished six different
\end{abstract}

Electronic supplementary material The online version of this article (doi:10.1007/s00401-013-1116-7) contains supplementary material, which is available to authorized users.

T. Misu $\cdot$ K. Fujihara

Department of Multiple Sclerosis Therapeutics, Tohoku

University Graduate School of Medicine, Sendai, Japan

\section{R. Höftberger}

Institute of Neurology, Medical University of Vienna,

Vienna, Austria

I. Wimmer · M. Bradl $\cdot$ H. Lassmann $(\bowtie)$

Department of Neuroimmunology, Center for Brain Research,

Medical University of Vienna, Spitalgasse 4, 1090 Wien, Austria

e-mail: hans.lassmann@meduniwien.ac.at

Y. Takai $\cdot$ S. Nishiyama $\cdot$ M. Aoki

Department of Neurology, Tohoku University Graduate School

of Medicine, Sendai, Japan

I. Nakashima $\cdot$ H. Konno

Department of Neurology, National Nishitaga Hospital,

Sendai, Japan

F. Garzuly

Department of Pathology, Markusovszky Hospital,

Szombathely, Hungary

Y. Itoyama

National Center Hospital NCNP, Tokyo, Japan lesion types. The first reflects complement deposition at the surface of astrocytes, associated with granulocyte infiltration and astrocyte necrosis and followed by demyelination, global tissue destruction and the formation of cystic, necrotic lesions (lesion type 2). Such destructive lesions lead to Wallerian degeneration in lesion-related tracts (lesion type 3). Around active NMO lesions AQP4 may selectively be lost in the absence of aquaporin 1 (AQP1) loss or other structural damage (lesion type 4). Another pattern is characterized by clasmatodendrosis of astrocytes, defined by cytoplasmic swelling and vacuolation, beading and dissolution of their processes and nuclear alterations resembling apoptosis, which was associated with internalization of AQP4 and AQP1 and astrocyte apoptosis in the absence of complement activation. Such lesions give rise to extensive astrocyte loss, which may occur in part in the absence of any other tissue injury, such as demyelination or axonal degeneration (lesion type 5). Finally, lesions with a variable degree of astrocyte clasmatodendrosis are found, which show plaquelike primary demyelination that is associated with oligodendrocyte apoptosis, but with preservation of axons (lesion type 6). In active multiple sclerosis (MS) lesions astrocytes reveal changes of reactive protoplasmatic or fibrillary gliosis. Only in a subset of lesions, in patients with aggressive disease, loss of AQP4 is observed in the initial stage of their formation, which is associated with retraction of astrocyte processes in the absence of complement deposition, granulocyte infiltration or loss of AQP1 or astrocytes. Our data underline the primary assault of astrocytes in NMO lesions, but also indicate that different mechanisms of tissue injury operate in parallel in the same patient and even within the same lesion.

Keywords Neuromyelitis optica - Astrocytes · Demyelination · Complement 


$\begin{array}{ll}\text { Abbreviations } \\ \text { AQP1 } & \text { Aquaporin 1 } \\ \text { AQP4 } & \text { Aquaporin 4 } \\ \text { GFAP } & \text { Glial fibrillary acidic protein } \\ \text { NMO } & \text { Neuromyelitis optica } \\ \text { MS } & \text { Multiple sclerosis } \\ \text { EAAT2 } & \text { Excitatory amino acid transporter 2 } \\ \text { CNS } & \text { Central nervous system } \\ \text { PBS } & \text { Phosphate buffered saline } \\ \text { FCS } & \text { Fetal calf serum }\end{array}$

\section{Introduction}

Neuromyelitis optica (NMO) is a chronic inflammatory disease of the central nervous system, resulting in demyelinating and destructive lesions predominantly in the spinal cord and the optic system [6, 28]. Recently, auto-antibodies directed against the astrocyte water channel aquaporin 4 (AQP4) have been discovered in NMO patients, which turned out to be a highly specific and sensitive paraclinical diagnostic marker of the disease $[11,25,26]$. Furthermore, the potential pathogenicity of these auto-antibodies has been shown in in vitro and in vivo experiments $[2,3,20,42,46]$. From these data it is now well established that AQP4 antibodies, when getting access to the central nervous system compartment in vivo, can destroy astrocytes [8]. It is assumed that the antibodies drive complement-dependent lysis, and that granulocytes and eosinophils recruited into the lesions are major effector cells [42]. Demyelination and axonal destruction may in part be mediated by excitotoxic mechanisms, which may develop when the excitatory amino acid transporter 2 (EAAT2) is lost from dysfunctional astrocytes $[13,30]$. In addition, loss of AQP4 from astrocytes may disturb water homeostasis and result in brain edema $[12,14]$. However, to what extent these concepts, mainly developed in in vitro models, are also operating in the patient's lesions in vivo, is less clear. In addition, it remains to be determined, whether similar mechanisms of tissue injury are also relevant for the development of demyelinating lesions in multiple sclerosis patients [38]. This question has gained further attention, since it has recently been described that about half of all MS patients have circulating autoantibodies against a potassium channel expressed on astrocytic foot processes (Kir 4.1 ), and that these antibodies may destroy astrocytes in vitro in a complement-dependent manner [50]. In this study we performed a detailed comparison of astrocyte pathology in relation to demyelination and neurodegeneration in active NMO and MS lesions. As described before [31, 35, 36, 43], our studies show that astrocyte pathology is unique and highly characteristic in NMO, but that different mechanisms lead to astrocyte destruction, demyelination and neurodegeneration. In contrast, we did not find evidence for antibody or complementmediated astrocyte injury in MS lesions.

\section{Materials and methods}

Cases and material

This study was performed on paraffin-embedded, formalinfixed archival material of active lesions from NMO patients $(n=7)$, from multiple sclerosis patients, including acute MS $(n=6)$, secondary progressive MS $(n=6)$ and primary progressive MS $(n=6)$, and non-neurological controls $(n=3$; Table 1$)$. The cases were selected from a much larger sample of archival autopsy material, collected in the Department of Neurology at the Tohoku University School of Medicine and the Brain Research Institute at the University of Vienna, on the basis of presence of active lesions and suitability for detailed immunohistochemical investigations. From the NMO cases, four cases fulfilled the Wingerchuck [56] clinical criteria of definite $\mathrm{NMO}(499,216, \mathrm{~A} 10-42$ and 2001-50), two of a limited form of NMO (12193 and A1036 ) and one case (24-81) presented with a single destructive lesion in the medulla oblongata, with NMO typical pathology [28]. Since half of the NMO patients died before tests for AQP4 antibodies were available, pathological diagnostic criteria for NMO were used, which included lesional topography, the presence of longitudinally extensive lesions in the spinal cord mainly affecting grey matter, of active lesions with marked inflammation and tissue damage in vasculocentric pattern, and/or destructive inflammatory lesions with extensive loss of astrocytes, associated with demyelination and profound axonal destruction [28]. In contrast, all MS patients showed focal inflammatory demyelinating lesions throughout the central nervous system (CNS) and a variable extent of cortical demyelination and diffuse white matter injury [22]. In addition, clinical history and results of whole body autopsy, where available, were reviewed. The study was approved by the Ethic Commission of the Medical University of Vienna (Nr. 087/01/2012) and the Tohoku University Graduate School of Medicine (No. 2009-143/2011-74).

\section{Neuropathological techniques and immunohistochemistry}

The brain and spinal cords were fixed with $10 \%$ formalin and multiple tissue blocks were embedded in paraffin. Tissue slices of 4-6 $\mu \mathrm{m}$ thickness were cut and mounted serially on numbered slides. Histological examinations were performed by hematoxylin and eosin (HE), KlüverBarrera (KB), and Bielschowsky's silver impregnation axonal stain. 
Table 1 Demographics of NMO, MS and control patients

\begin{tabular}{|c|c|c|c|c|c|c|}
\hline Case & Age & Gender & Dis.Dur. & AQP-4 Ab & Les. Location & Les. Type \\
\hline 499 & 20 & Female & 4 years & n.d. & $\mathrm{SC}, \mathrm{O}$, Brain & $1,2,3,4,5,6$ \\
\hline 216 & 30 & Female & 5 years & n.d. & SC, Med. & $1,2,4,5$ \\
\hline $24-81$ & 46 & Female & 0.5 months & n.d. & Med. & 1,2 \\
\hline 12193 & 57 & Female & 8 months & Positive & SC, Med. & $2,4,5,6$ \\
\hline A10-42 & 75 & Female & 21 years & Positive & $\mathrm{SC}, \mathrm{O}$ & 4 \\
\hline A10-36 & 82 & Female & 10 years & Positive & SC, Brain & 4,6 \\
\hline $2001-50$ & 63 & Female & 20 years & n.d. & $\mathrm{SC}, \mathrm{O}$ & $1,2,3,4,5,6$ \\
\hline AMS 1 & 34 & Female & 4 months & n.d. & Brain & DM, p. AQP4 loss \\
\hline AMS 2 & 35 & Male & 1.5 months & n.d. & SC, Med, Brain & DM, p. AQP4 loss \\
\hline AMS 3 & 45 & Male & 0.2 months & n.d. & Brain & DM, p. AQP4 loss \\
\hline AMS 4 & 45 & Male & 0.6 months & n.d. & Brain & DM, p. AQP4 loss \\
\hline AMS 5 & 52 & Male & 1.5 months & n.d. & Brain & DM, RG \\
\hline AMS 6 & 78 & Male & 2 months & n.d. & Med, Brain & $\mathrm{DM}, \mathrm{RG}$ \\
\hline SPMS 1 & 34 & Male & 120 months & n.d. & SC, Med, Brain & DM, RG \\
\hline SPMS 2 & 41 & Male & 137 months & n.d. & Med, Brain & $\mathrm{DM}, \mathrm{RG}$ \\
\hline SPMS 3 & 46 & Female & 444 months & n.d. & SC, Med, Brain & $\mathrm{DM}, \mathrm{RG}$ \\
\hline SPMS 4 & 53 & Female & 241 months & n.d. & Brain & $\mathrm{DM}, \mathrm{RG}$ \\
\hline SPMS 5 & 56 & Male & 372 months & n.d. & Med, Brain & $\mathrm{DM}, \mathrm{RG}$ \\
\hline SPMS 6 & 66 & Female & 96 months & n.d. & Brain & $\mathrm{DM}, \mathrm{RG}$ \\
\hline PPMS 1 & 34 & Male & 204 months & n.d. & Med, Brain & $\mathrm{DM}, \mathrm{RG}$ \\
\hline PPMS 2 & 53 & Male & 168 months & n.d. & Brain & $\mathrm{DM}, \mathrm{RG}$ \\
\hline PPMS 3 & 54 & Female & 72 months & n.d. & Brain & $\mathrm{DM}, \mathrm{RG}$ \\
\hline PPMS 4 & 55 & Female & 60 months & n.d. & Brain & $\mathrm{DM}, \mathrm{RG}$ \\
\hline PPMS 5 & 67 & Male & 87 months & n.d. & Med, Brain & DM, RG \\
\hline PPMS 6 & 71 & Female & 264 months & n.d. & Brain & $\mathrm{DM}, \mathrm{RG}$ \\
\hline $\mathrm{CO} 1$ & 39 & Female & 0 & n.d. & & 0 \\
\hline $\mathrm{CO} 2$ & 45 & Female & 0 & n.d. & & 0 \\
\hline $\mathrm{CO} 3$ & 30 & Female & 0 & n.d. & & 0 \\
\hline
\end{tabular}

Dis.Dur disease duration, Les.Locat lesion location, Les.Type lesional type, $A M S$ acute multiple sclerosis, SPMS secondary progressive multiple sclerosis, $P P M S$ primary progressive multiple sclerosis, $C O$ controls, $S C$ spinal cord, $O$ optic nerve, $M e d$ medulla oblongata, $D M$ demyelinated lesions, $p A Q P 4$ loss partial aquaporin 4 loss, $R G$ reactive gliosis

Sections were deparaffinized twice with xylol substitute (XEM) (Fluka analytical, Germany) for $20 \mathrm{~min}$ each, rinsed twice in $96 \%$ ethanol, treated with hydrogen peroxide in methanol for 30 min to block endogenous peroxidases, rehydrated in a descending series of ethanol and further incubated for $1 \mathrm{~h}$ in phosphate buffered saline containing $10 \%$ fetal calf serum (PBS/FCS) to block nonspecific antibody binding. Antigen retrieval was performed by heating the sections for 60-90 min in EDTA (1 mM EDTA, $10 \mathrm{mM}$ Tris, $\mathrm{pH} 8.5$ or 9) or $0.1 \mathrm{mM}$ citrate buffer (pH 6) in a household food steamer device. The primary antibodies (Table 2) were applied overnight in PBS/FCS. Afterwards, the slides were washed 3-4 times in PBS. Then the slides were incubated with biotinylated secondary antibodies (sheep anti-mouse, donkey anti-rabbit, donkey anti-goat; all from Amersham or Jackson ImmunoResearch) for $1 \mathrm{~h}$ at room temperature. After washing 3-4 times in PBS, the sections were treated with avidin peroxidase (diluted 1:100 in $10 \%$ FCS/PBS), and incubated for $1 \mathrm{~h}$ at room temperature. For visualization of the bound antibodies, diaminobenzidine (DAB) was used as chromogen.

For double staining, we combined two enzyme systems, peroxidase and alkaline phosphatase. After the single staining procedure using anti-mouse antibody, we further applied rabbit anti-human antibody and then incubated the sections with AP-conjugated anti-rabbit IgG and stained by Vector blue. Counter staining was done by hematoxylin or nuclear fast red, where applicable.

In human brain and spinal cord tissue astrocytes express besides AQP4 another water channel, i.e. aquaporin 1 (AQP1; Supplementary Figure 1; [48]). This is different from rodent CNS tissue, where AQP1 is exclusively expressed on the epithelial cells of the choroid plexus [24]. Since AQP1 is highly expressed in the human CNS in areas, 
destined to develop NMO lesions (Supplementary Figure 1) and is also present on the surface of astrocytes within NMO lesions, we used this protein as an additional marker to analyse the astrocyte reaction within the lesions.

\section{TUNEL staining}

For the detection of cell death, we used the in situ cell death detection kit AP (Roche Applied Science, German). Briefly, dewaxed and rehydrated sections were covered by TUNEL reaction mixture for $60 \mathrm{~min}$. After washing with PBS for 3 times, converter-AP was added on the slides for $30 \mathrm{~min}$. After washing, the immunostaining was performed by Vector blue.

\section{Results}

Global pathology of active NMO lesions

Active lesions in both NMO and MS were defined by the presence of early CNS protein reactive degradation products in macrophages, as defined before in multiple sclerosis lesions [4]. In contrast to MS lesions, macrophages in
Fig. 1 Different lesion types in the central nervous system of NMO patients: a-h distribution of different lesion types in the spinal cord of patients with neuromyelitis optica (patient 499, spinal cord). The different lesion types are characterized by different types of astrocyte pathology, demyelination, axonal injury, inflammation and complement C9neo deposition. The position of different lesion types, as characterized in detail in Figs. 1 and 2 are labeled by numbers in the sections stained for myelin $(\mathbf{a}) ; \times 5$. $\mathbf{i}-\mathbf{q}$ Lesion type 1 is defined by extensive complement deposition and granulocyte infiltration (i); astrocytes are in part preserved and express AQP1, but have nearly completely lost AQP4 (j-l); degenerating astrocytes show C9neo reactivity on their surface $(\mathbf{m})$ and fragmented TUNEL-positive DNA in the nucleus and dispersed in the cytoplasm, suggesting necrotic cell death (n); myelin (o) and axons (p) are partly preserved, but dystrophic swollen axonal spheroids are present $(\mathbf{p})$, which have accumulated amyloid precursor protein (APP; $\mathbf{q})$. $\mathbf{i}-\mathbf{l}$ and $\mathbf{o}-\mathbf{q} \times 250 ; \mathbf{m}$, $\mathbf{n} \times 1,100 ; \mathbf{r}-\mathbf{w}$ lesion type 2 reflects a destructive lesion with extensive loss of astrocytes (r, s), and liberation of GFAP rich exudates into the extracellular space (r); insert in $\mathbf{r}$ shows complement $\mathrm{C} 9$ neo in macrophages; more advanced lesions $\mathbf{t}-\mathbf{w}$ show cystic cavities with some macrophages and tissue bridges containing astrocytes $(\mathbf{u})$, which have lost AQP4 (v) and axons (w), but being devoid of myelin myelin (t); $\mathbf{r}, \mathbf{s} \times 150 ; \mathbf{t}-\mathbf{w} \times 250$

active NMO lesions also contained GFAP reactive degradation products. All NMO cases included in this sample contained active lesions together with inactive destructive or demyelinated lesions at other sites of the central nervous

Table 2 Antigen retrieval and primary antibodies

\begin{tabular}{|c|c|c|c|c|c|}
\hline Antibody & Origin & Target & Dilution & Antigen retrieval & Source \\
\hline AQP-1 & Rabbit (pAB) & Aquaporin-1 & $1: 500$ & 0 & $\begin{array}{l}\text { Sc-20810; Santa Cruz, } \\
\text { USA }\end{array}$ \\
\hline AQP-4 & Rabbit (pAB) & Aquaporin 4 & $1: 250$ & 0 & $\begin{array}{l}\text { Sigma-Aldrich, St. Louis, } \\
\text { USA }\end{array}$ \\
\hline C9neo & Rabbit (pAB) & Complement component $\mathrm{C} 9$ & $1: 2,000$ & $\mathrm{P}$ & [39] \\
\hline CD68 & Mouse (mAB) & $\begin{array}{l}\text { 110-kD Transmembrane } \\
\text { glycoprotein }\end{array}$ & $1: 100$ & St $(\mathrm{E})$ & $\begin{array}{l}\text { M0814; Dako, } \\
\text { Glostrup, Denmark }\end{array}$ \\
\hline GFAP & Rabbit (pAB) & $\begin{array}{l}\text { Glial fibrillary } \\
\text { acidic protein }\end{array}$ & $1: 3,000$ & St $(\mathrm{E})$ & $\begin{array}{l}\text { Z0334; Dako, Glostrup, } \\
\text { Denmark }\end{array}$ \\
\hline $\mathrm{Ig}$ & Sheep (pAB) & $\begin{array}{l}\text { Human } \\
\text { immunoglobulin }\end{array}$ & $1: 200$ & $\mathrm{P}$ & $\begin{array}{l}\text { RPM1003; Amersham } \\
\text { Pharmacia Biotech, } \\
\text { Buckinghamshire, UK }\end{array}$ \\
\hline MBP & Rabbit (pAB) & $\begin{array}{l}\text { Myelin basic } \\
\text { protein }\end{array}$ & $1: 2,500$ & 0 & $\begin{array}{l}\text { A0623; Dako, Glostrup, } \\
\text { Denmark }\end{array}$ \\
\hline NF & Rabbit (pAB) & $\begin{array}{l}\text { Neurofilament } \\
\text { medium chain }(150 \mathrm{kDa})\end{array}$ & $1: 2,000$ & St $(E)$ & $\begin{array}{l}\text { AB1981; Chemicon, } \\
\text { Temecula, CA, USA }\end{array}$ \\
\hline PLP & Mouse (mAB) & Proteolipid protein & $1: 1,000$ & St $(\mathrm{E})$ & $\begin{array}{l}\text { MCA839G; Serotec, } \\
\text { Düsseldorf, Germany }\end{array}$ \\
\hline MAG & Mouse (mAB) & $\begin{array}{l}\text { Myelin associated } \\
\text { glycoprotein }\end{array}$ & $1: 1,000$ & St $(E)$ & AB B11F7 [27] \\
\hline TPPP/p25 & Rabbit (pAB) & $\begin{array}{l}\text { Tubulin polymerization } \\
\text { promoting protein; } \\
\text { Oligodendrocytes }\end{array}$ & $1: 250$ & $\mathrm{St}(\mathrm{E})$ & [15] \\
\hline MOG & Mouse (mAB) & $\begin{array}{l}\text { Myelin associated } \\
\text { glycoprotein }\end{array}$ & $1: 1,000$ & St (C) & $\mathrm{AB} 8-18 \mathrm{C} 5$ [27] \\
\hline
\end{tabular}

$p A B$ polyclonal antibody, $m A B$ monoclonal antibody, $S t$ antigen retrieval in steamer, $E$ EDTA buffer, $C$ citrate buffer, $P$ antigen retrieval with protease 

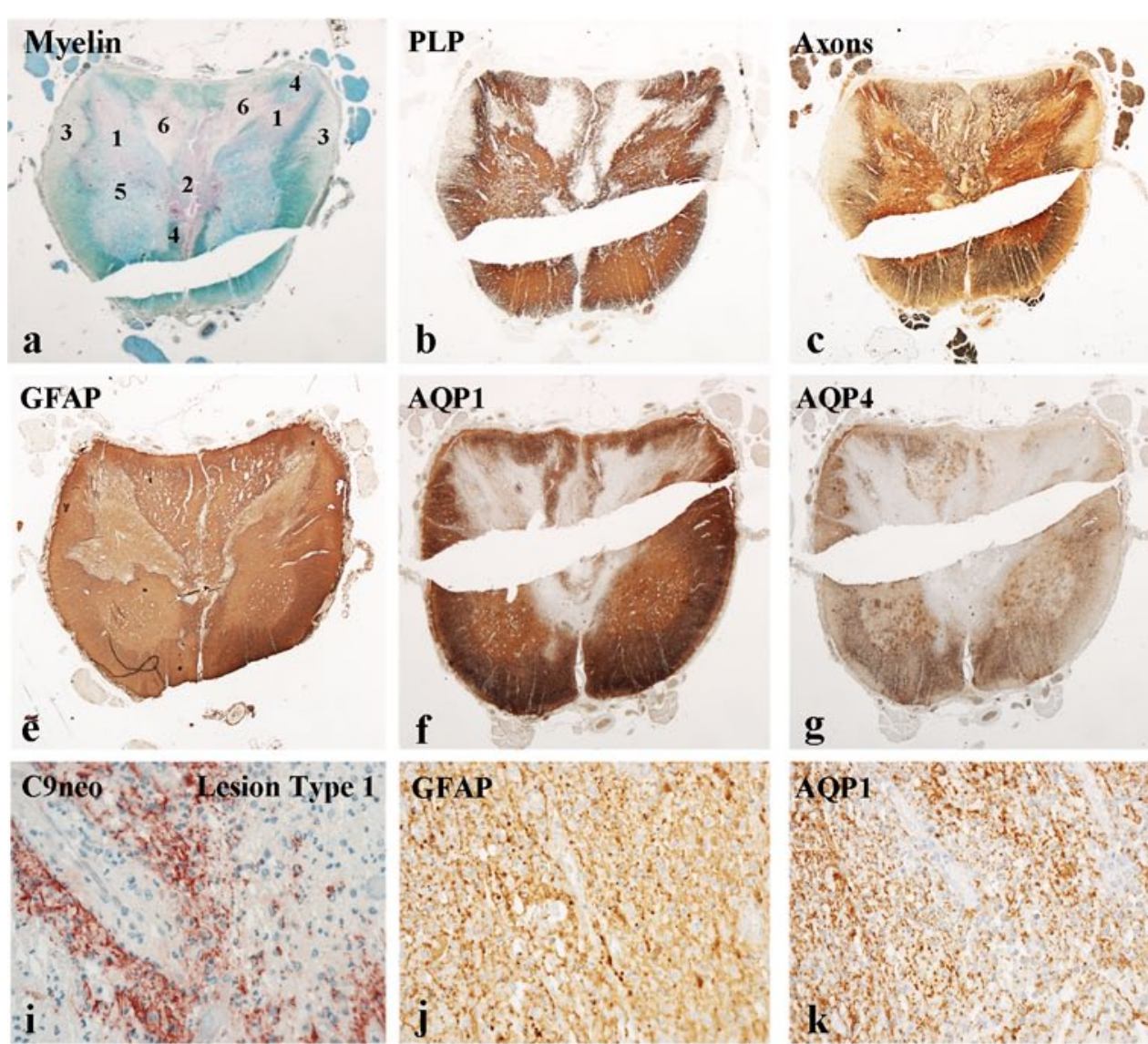

\section{C9neo}

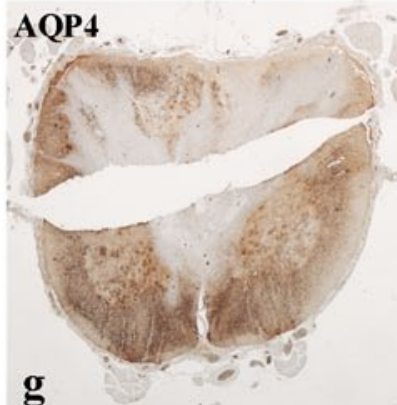

d

CD68

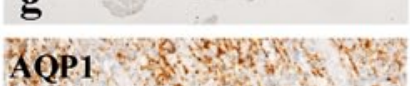

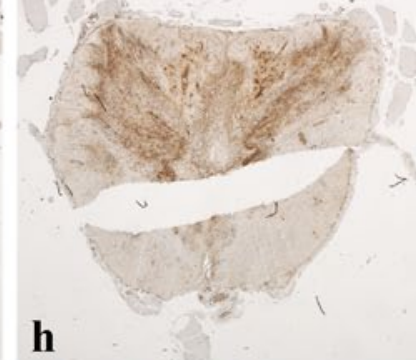

AQP4
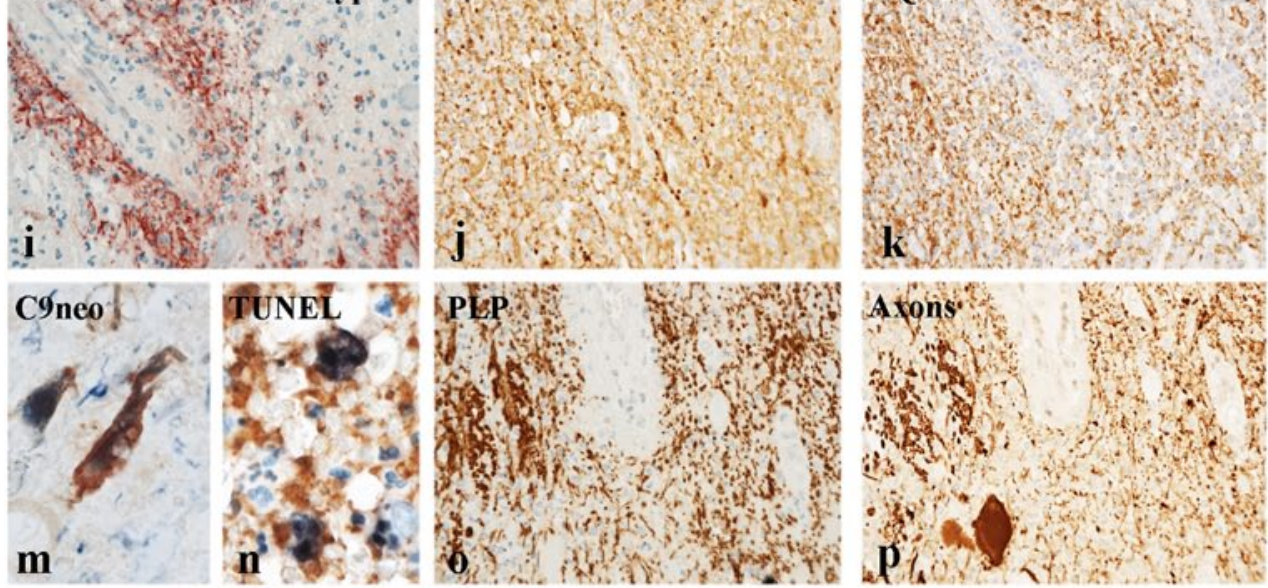

I

APP

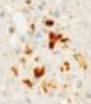

$\mathbf{q}$

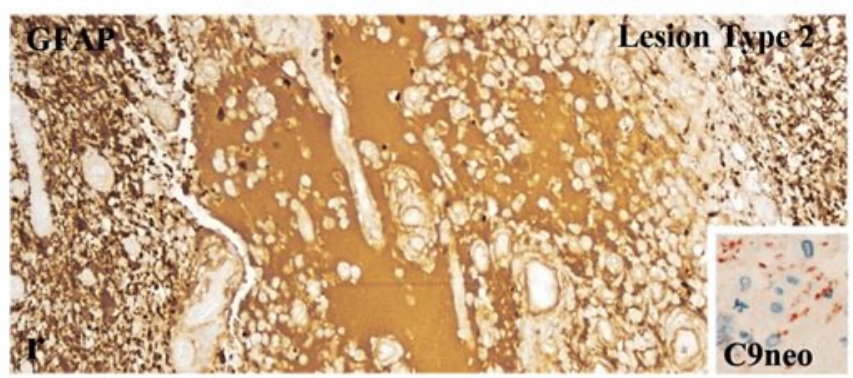

\section{AQP1}
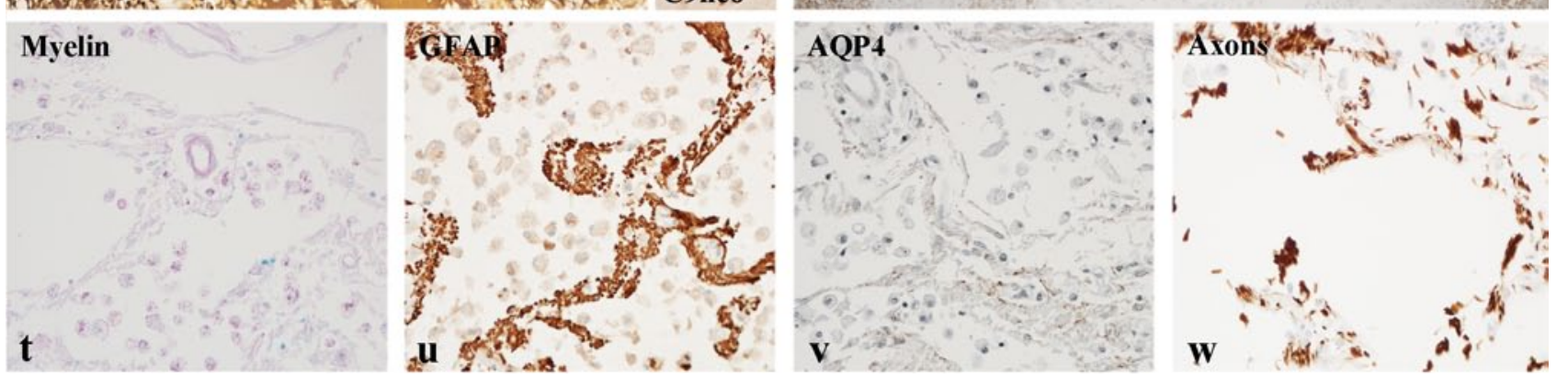
system (Fig. 1). Active lesions in NMO showed profound inflammation. Inflammatory infiltrates were composed of $\mathrm{T}$ lymphocytes, B lymphocytes and macrophages. Profound microglia activation was seen in the periplaque white matter in both conditions. Inflammatory infiltrates were in part concentrated around vessels (perivascular cuffs) and in part dispersed throughout the lesion parenchyme. Abundant neutrophilic granulocytes and some eosinophils were present in a subset of active NMO lesions [28].

A more detailed inspection of sections with active NMO lesions, however, revealed that at least six different lesion types were present, suggesting different type- and stagespecific patterns of tissue injury (Table 3). They differed in the extent of complement deposition, granulocyte infiltration, acute astrocyte alterations, astrocyte loss, demyelination and axonal injury. They were found in the spinal cord and brain stem of all patients and also, when lesions were present at all, in the forebrain (Supplementary Figure 2). The different lesion types appeared in part side by side within the same tissue block (Fig. 1a-h), but their relative number in different brain regions of the same patient and of different patients varied (Supplementary Figure 2).

\section{Active NMO lesions associated with complement activation and granulocyte infiltration (lesion type 1)}

The first lesion type was characterized by massive deposition of immunoglobulins and activated complement and high infiltration of the tissue by granulocytes (Fig. 1i). In such lesions astrocytes and their processes were covered in part with activated complement (Fig. 1m), and perivascular astrocyte processes were partly lost. The remaining GFAP positive astrocytes did not show AQP4 on their surface, but in part still expressed AQP1 (Fig. 1j-l). TUNEL staining showed DNA fragmentation in the nuclei of such astrocytes and TUNEL-positive DNA was also diffusely dispersed within the cytoplasm, a pattern characteristic for cell necrosis (Fig. 1n). Myelin and axons were relatively spared in comparison to astrocyte loss, but active demyelination and axonal injury was documented by apoptotic oligodendrocytes and by the presence of macrophages with early myelin degradation products together with acutely injured axons with accumulation of amyloid precursor protein and neurofilament reactivity in axonal spheroids (Fig. 1o-q). Analysis of different myelin antigens revealed little or no loss of myelin basic protein, proteolipid protein or myelin oligodendrocyte glycoprotein, while myelin associated glycoprotein was lost from most myelin sheaths [5] and oligodendrocytes were massively reduced in numbers within the lesions (Supplementary Figure 3).

\section{Cystic lesions with extensive tissue destruction (lesion type 2)}

In these areas most cellular components were lost and replaced by fluid filled cysts, which contained a variable number of macrophages and vessels with perivascular fibrosis (Fig. 1r-w). If such lesions still contained active areas of lesion type 1, C9neo antigen was present on astrocyte processes or in degradation products in macrophages at the
Table 3 Key pathological features of different lesions types in NMO
Les.Type lesion type, $T \mathrm{~T}$ cells, $\mathrm{Gr}$ granulocytes, $C 9 n$ complement $\mathrm{C} 9$ neo antigen, $A G$ astroglia pathology, Demy demyelination, $O G$ loss loss of oligodendrocytes, Ax. Loss axonal loss

\pm , minor or absent; + , minor;

++ , moderate; +++ , severe

\begin{tabular}{|c|c|c|c|c|c|c|c|}
\hline Les. Type & $\mathrm{T}$ & $\mathrm{Gr}$ & $\mathrm{C} 9 \mathrm{n}$ & $\mathrm{AG}$ & Demy & OG loss & $\begin{array}{l}\text { Ax } \\
\text { loss }\end{array}$ \\
\hline 1 & ++ & +++ & +++ & $\begin{array}{l}\text { Necrosis } \\
\text { AQP4 variable } \\
\text { AQP1 variable } \\
\text { GFAP variable }\end{array}$ & + & Apo & + \\
\hline 2 & $+/++$ & \pm & \pm & $\begin{array}{l}\text { AQP4 loss } \\
\text { AQP1 loss } \\
\text { GFAP loss }\end{array}$ & Complete & +++ & +++ \\
\hline 3 & - & - & - & React. gliosis & +++ & ++ & +++ \\
\hline 4 & \pm & - & - & $\begin{array}{l}\text { AQP4 loss } \\
\text { Clasmatodendrosis + }\end{array}$ & - & - & - \\
\hline 5 & ++ & - & - & $\begin{array}{l}\text { Clasmatodendrosis }+++ \\
\text { AQP4 loss } \\
\text { AQP1 loss } \\
\text { GFAP loss }\end{array}$ & - & - & - \\
\hline 6 & ++ & - & - & $\begin{array}{l}\text { Clasmatodendrosis }+/++ \\
\text { AQP4 loss variable } \\
\text { AQP1 loss variable } \\
\text { GFAP loss } \pm\end{array}$ & Complete & +++ & ++ \\
\hline
\end{tabular}


lesion borders. Within the inactive center of such lesions some bridges of preserved tissue remained between the cystic cavities, which contained astrocytes and axons, but no myelin sheaths and only sparse oligodendrocytes (Supplementary Figure 3). AQP1 and AQP4 expression was largely lost within cystic lesions. When such lesions were present side by side with active lesions the cysts contained a protein-rich fluid, which was highly reactive for GFAP but not for aquaporins (Fig. 1r, s). This was no longer the case in more advanced destructive lesions (Fig. 1t-w).

\section{Lesions resembling secondary Wallerian degeneration (lesion type 3)}

Such lesions were present in white matter tracts of the spinal cord. They showed an extensive loss of myelin, oligodendrocytes and axons and a profound fibrillary gliosis with densely packed GFAP and AQP1 reactive astrocytic processes, while loss of AQP4 was variable (Fig. 2a-c, Supplementary Figure 3).

\section{Lesions with selective loss of AQP4 in the absence of other structural damage (lesion type 4)}

This pattern of tissue injury was frequently seen in the vicinity of active NMO lesions. They were associated with mild to moderate perivascular inflammatory infiltrates and a variable degree of microglia activation, but no complement deposition or granulocyte infiltration. In sections stained for conventional cellular markers, myelin or axons, no pathological alterations were seen (Fig. 2d, Supplementary Figure 3). However, immunohistochemistry for AQP4 revealed profound or even complete loss of this protein on astrocytes, which still normally expressed AQP1 and GFAP. GFAP positive astrocytes either showed a normal structure and the presence of cell processes within the perivascular glia limitans. However, some of them were enlarged with increased perinuclear GFAP reactivity and contained intracytoplasmic granular AQP4 reactivity, suggesting endocytotic uptake (Fig. 2d-g) probably due to the AQP4Abinduced internalization.

\section{Active NMO lesions with astrocytic clasmatodendrosis (lesion type 5)}

In these lesions, inflammatory infiltrates mainly consisted of $\mathrm{T}$ cells and macrophages. Reactivity for activated terminal complement on astrocytes and granulocyte infiltration were absent at the site of astrocyte injury. The characteristic hallmark of such lesions was the accumulation of bizarre astrocytes with massively enlarged peri-nuclear cytoplasm, presence of intra-cytoplasmic vacuoles and retraction, beading and clumping of the cell processes. AQP4 reactivity was partially lost from the surface of such astrocytes, but the cells contained abundant intracellular granules, reactive for AQP4, AQP1 and immunoglobulins. Many of these cells showed dense and condensed nuclei with DNA fragmentation, thus resembling apoptotic cells. Myelin sheaths, reactive for MBP, PLP and MAG, oligodendrocytes and axons were well preserved in the majority of these lesions, thus the presence of such lesions was not visible in sections stained for myelin (Fig. 2h-q, Supplementary Figure 3).

\section{Lesions with astrocyte dystrophy and primary demyelination (lesion type 6)}

These lesions were sharply demarcated areas of complete demyelination, loss of oligodendrocytes and axonal preservation (Fig. 2r-y, Supplementary Figure 3). Active demyelination was reflected by the presence of macrophages with early myelin degradation products. Also in these lesions prominent inflammation was present mainly consistent of $\mathrm{T}$ cells and macrophages. Granulocytes and deposition of activated complement were absent. GFAP positive astrocytes were present in the lesions in variable extent, and immunoreactivity for AQP1 and AQP4 showed more pronounced reduction compared to GFAP. Furthermore, astrocyte clasmatodendrosis, as described in lesion type 2, was seen in some of the remaining GFAP positive astrocytes.

\section{Astrocyte pathology in multiple sclerosis lesions}

Active lesions dominated the pathology of acute MS (Fig. 3), although also a variable number of inactive lesions were present. In patients with progressive MS, classical active lesions were rare, while slowly expanding as well as inactive lesions were seen in variable numbers [21]. Active as well as slowly expanding lesions showed inflammation, mainly consistent of $\mathrm{T}$ cells and macrophages/microglia [7], but granulocytes and eosinophils were rarely seen. As described in detail before ([23], Fig. 3a-c) primary demyelination with oligodendrocyte apoptosis was the hallmark of initial tissue injury in active MS lesions. Furthermore, preferential loss of myelin-associated glycoprotein was prominent in active lesions of acute MS [27].

Concerning astrocytes, slowly expanding and inactive lesions in MS showed the MS-typical glial scar. Reactive astrocytes expressed GFAP, AQP4 and AQP1. However in a subset of fulminate active lesions in acute MS, loss of AQP4 was encountered, associated with the appearance of large protoplasmatic, sometimes multi-nucleated astrocytes, with retraction of perivascular astrocytic foot processes from the glia limitans (Fig. 3; [32, 33, 49]). These protoplasmatic astrocytes were intensely stained for GFAP and highly expressed AQP1. Furthermore, in immediately adjacent areas massive over-expression of AQP4 was seen around the 

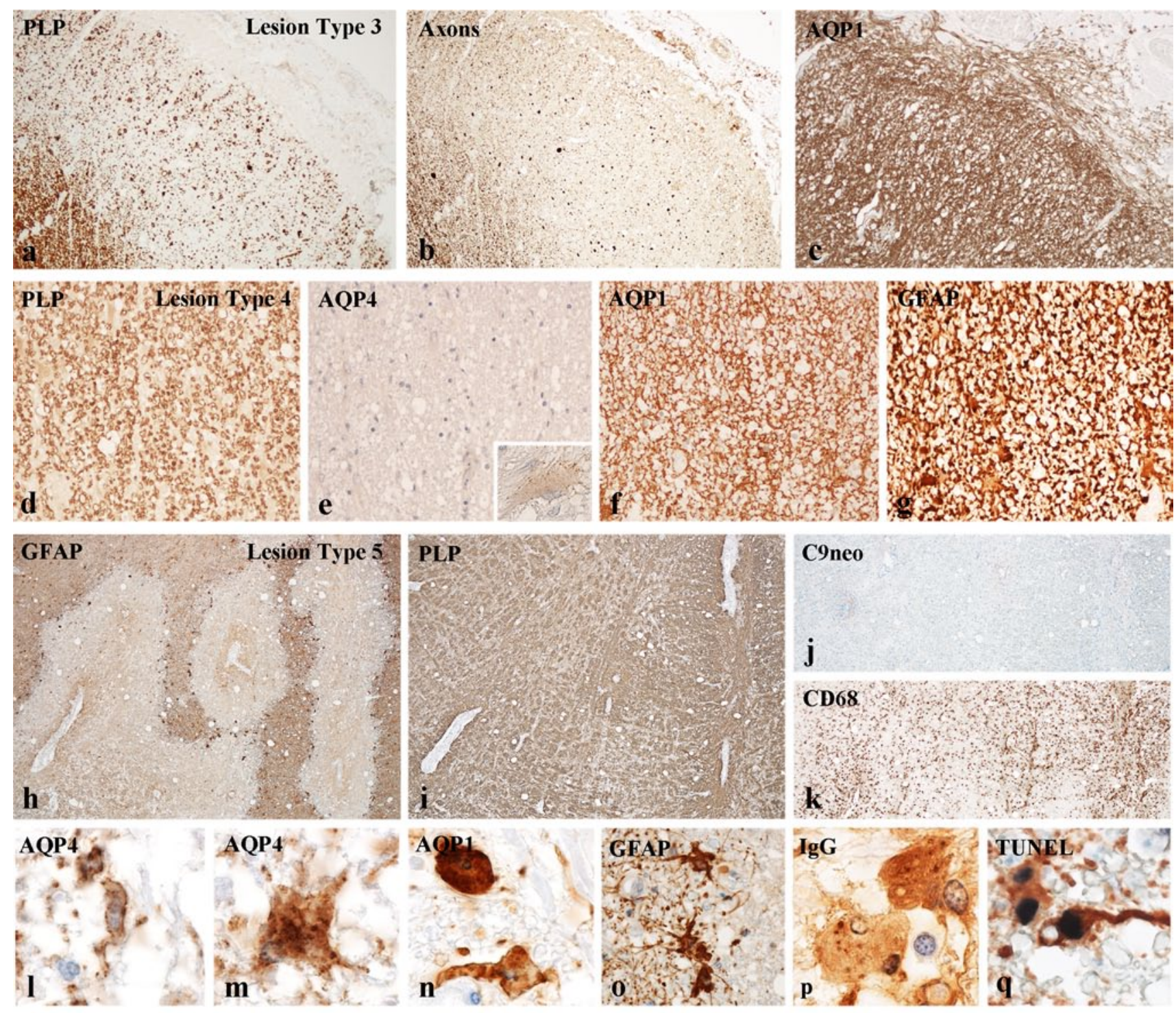

k.
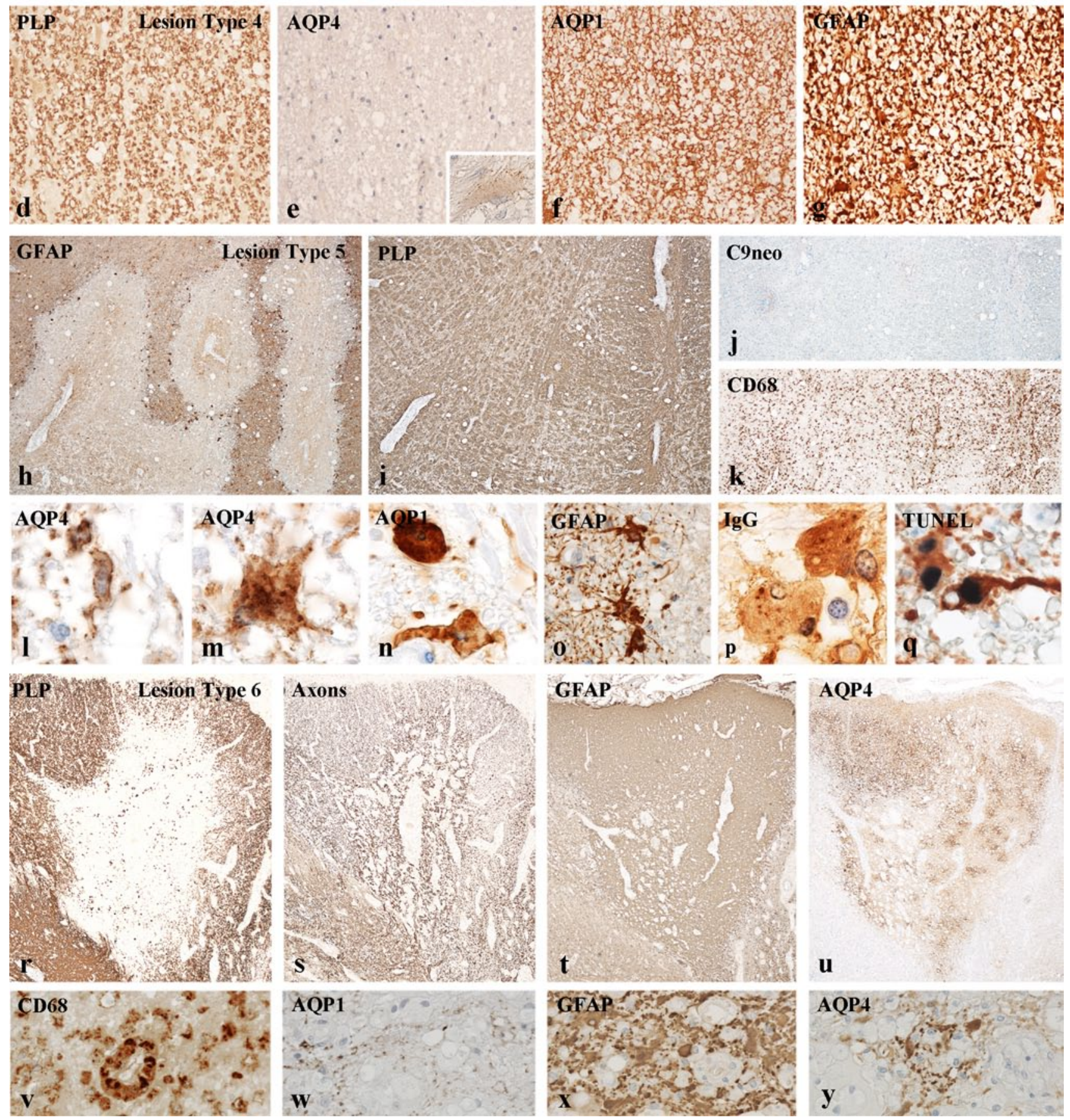

u

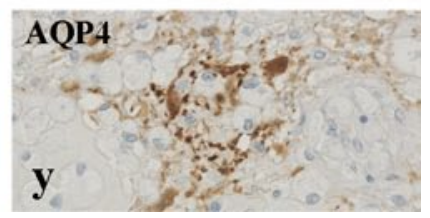


4 Fig. 2 Different lesion types in the central nervous system of NMO patients [2]: a-c lesion type 3 represents areas of Wallerian degeneration; myelin sheaths (a) and axons (b) are lost in comparable degree; there is profound astrocytic gliosis (c); the astrocytes express GFAP and AQP1 and 4; (patient 499, spinal cord) $\times 30$. d-g Lesion type 4 shows selective loss of AQP4 (e), while myelin sheaths (d), axons and neurons remain preserved; reactive astrocytes express GFAP (g) and AQP1 (f); some astrocytes also show granular intra-cytoplasmic reactivity for AQP4 (e, insert); (patient 499 spinal cord), $\times 250$; insert: $\times 1,100$. h-q lesion type 5 shows extensive loss of astrocytes (h) and astrocytic clasmatodendrosis $(\mathbf{l}-\mathbf{q})$, while myelin sheaths (i) and axons are preserved; there is profound macrophage infiltration (k), but no deposition of activated complement or granulocyte infiltration $(\mathbf{j})$; astrocyte clasmatodendrosis is characterized by enlargement or peri-nuclear astrocyte cytoplasm and clumping and beading of cell processes (1-q), granular internalization of AQP1 $(\mathbf{n}), \mathrm{AQP} 4(\mathbf{l}, \mathbf{m})$ and $\operatorname{IgG}(\mathbf{p})$ and condensed nuclei (m, n, p) with DNA fragmentation (apoptosis; $\mathbf{q}$ ); $\mathbf{h}-\mathbf{k}$ (patient 216, medulla); $\times 50 ; \mathbf{l}-\mathbf{q} \times 1,100$. $\mathbf{r}-\mathbf{y}$ Lesion type 6 is characterized by selective primary demyelination (r), axonal preservation (s), profound astrocytic gliosis $(\mathbf{t})$ and a variable expression of AQP4 (u). AQP4 is lost in adjacent areas, which show features of complement-mediated active tissue destruction (adjacent lesion 1; Fig. 1a) or a destructive lesion pattern 2 (adjacent lesion 2, Fig. 1a); active demyelination is associated with macrophage infiltration (v); astrocytes show partial loss of AQP4 (y) and AQP1 (w) and some astrocytes with clasmatodendrosis ( $\mathbf{x}, \mathbf{y}) ; \mathbf{r}-\mathbf{u}$ (patient 499, spinal cord); $\times 20 ; \mathbf{v}-\mathbf{y} \times 150$ cell body and proximal processes of some of the reactive astrocytes. Morphological signs of necrosis or apoptosis as well as evidence for DNA fragmentation in astrocytes were absent and no activated complement was detected on these cells (Fig. 3d-g).

\section{Discussion}

The specific features in acute stages of NMO lesions are the loss of AQP4 [35, 36, 43] and the perivascular or subpial deposition of humoral factors such as immunoglobulin IgG and IgM, or activated complement (C9neo; [28, 43]). This apparently reflects a humoral immune attack against the glia limitans especially against the astrocyte foot processes by AQP4 reactive auto-antibodies. Based on these observations and experimental evidence it has been suggested that blockade of terminal complement activation, of Fc-receptor-mediated, antibody-dependent cellular cytotoxicity or of the recruitment of neutrophils and eosinophils should be followed as therapeutic strategies in NMO patients with active disease [42, 47, 53].

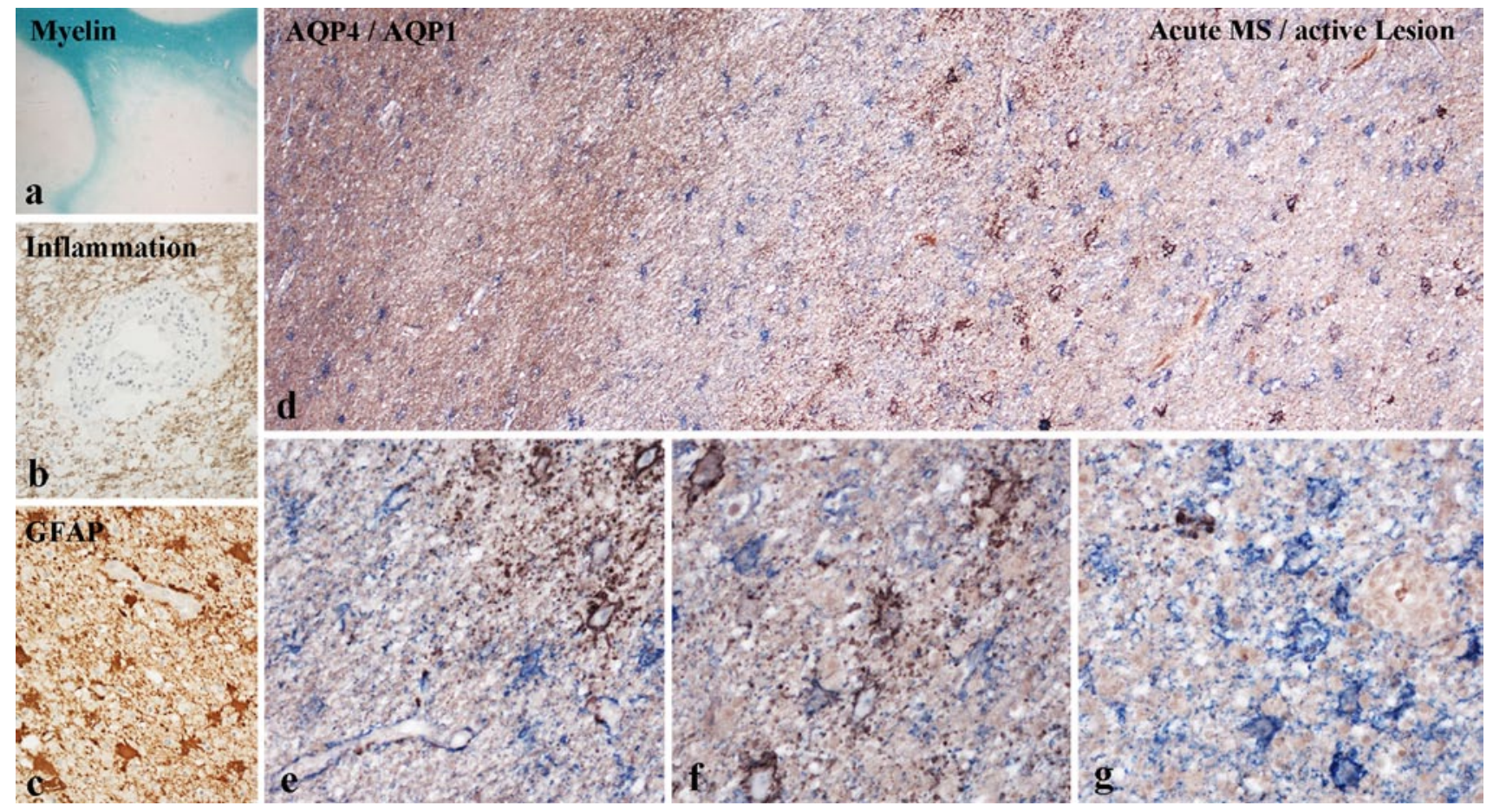

Fig. 3 Astrocyte pathology in an aggressive active demyelinating lesion of acute MS: a-c large subcortical lesion with ill defined borders and some concentric banding of demyelination at the lesion edge (a) is associated with profound inflammation (b) and protoplasmatic astrocyte reaction $(\mathbf{c})$. $\mathbf{a} \times 2 ; \mathbf{b}, \mathbf{c} \times 150$. d-g Astrocyte pathology shown by double staining for AQP1 (blue) and AQP4 (brown); in the normal appearing white matter reactive astrocytes express AQP1 and AQP4 (d, left); in the active zone there is a concentric layering of AQP4 loss (blue cells) and adjacent zones with AQP1-reactive astrocytes that strongly express AQP4; $\mathbf{e}-\mathbf{g}$ show higher magnifications of the areas shown in $\mathbf{d}$. $\mathbf{d} \times 300 ; \mathbf{e}-\mathbf{g} \times 900$ 
In this study, we show that tissue injury in the brain and spinal cord of NMO patients is complex and is mediated by at least two different mechanisms. In the first (lesion type I), active tissue injury is associated with antibody deposition and complement activation on astrocytes and their processes and this process is associated with profound recruitment of granulocytes and some eosinophils. This pattern can be well reproduced in in vivo rodent models, mediated by NMO antibodies in animals with autoimmune encephalomyelitis [3] as well as after local injection of NMO IgG into the mouse brain together with human complement [46]. Such lesions are in close topographical relation with inactive destructive lesions (lesion type 2) and we suggest that global overt tissue destruction and the formation of cystic cavities is the direct consequence of complement and granulocyte-induced tissue injury. In addition, the lack of astrocytes expressing the excitatory amino acid transporter (EAAT2) may promote excitotoxicity due to excess glutamate in the extracellular space $[13,30]$. Interestingly, the cystic cavities in early stages of destructive lesions contain a protein-rich fluid, which is highly reactive for GFAP. Thus, liberation of soluble GFAP through necrotic destruction of astrocytes may be the reason for high GFAP levels in the patient's cerebrospinal fluid during active phases of the disease $[37,51]$. Furthermore, extensive axonal destruction in such necrotizing lesions will result in secondary Wallerian tract degeneration in rostral or caudal segments of the spinal cord (lesion type 3).

A second type of lesions (type 4 and 5) apparently developed in the absence of complement activation and granulocyte infiltration at the site of active tissue injury. This type of tissue injury affected astrocytes leaving other components of the nervous tissue unaffected. It was reflected either by selective loss of AQP4 on astrocytes (lesion type 4) or by profound astrocyte loss associated with degenerative astrocyte alterations at the lesion edge (lesion type 5).

As described before [35, 36, 43] astrocytes, which are still preserved around NMO lesions, may lose AQP4 from their surface. The functional significance of pure AQP4 loss is currently not clear. It has been suggested that such astrocytes are functionally impaired with respect to control of water homeostasis [12], although these in vitro results could not be confirmed by others [44]. In addition, in the human brain and in such NMO lesions, but not in the rodent CNS, astrocytes also express AQP1, which is similarly efficient in regulating water transport in comparison to AQP4 [14].

In lesions with astrocyte loss, the characteristic hallmark for tissue injury was loss of AQP4 and a pattern of astrocyte dystrophy, which bears similarities to astrocyte clasmatodendrosis. Clasmatodendrosis was initially described in the beginning of the 20th century, as a regressive morphological change of astrocytes with cytoplasmic swelling and vacuolation with beading and dissolution of their dendritic processes [16]. Recently, clasmatodendrosis has been recognized to be associated with various diseases such as vascular diseases including Binswanger's leukoencephalopathy $[10,52]$ or epilepsy [19]. It appears to reflect a regressive change of astrocytes, which can be induced by several mechanisms, such as for instance energy deficiency [16, 19] or autophagic cell death [45], and which may finally result in astrocyte apoptosis [19]. In NMO this alteration of astrocytes seems to be directly induced by AQP4 antibodies in the absence of complement. This is supported by our finding that this type of astrocyte injury is associated with intra-cytoplasmic accumulation of AQP4, AQP1 and IgGpositive granules, apparently reflecting endosomal internalization of antibody-opsonized portions of the astrocyte cell membrane. Similar astrocyte changes have been described before in active NMO lesions [14]. We show further that many of the astrocytes with such alterations have shrunken, condensed and sometimes fragmented nuclei, which contain fragmented DNA. These changes are typical for apoptosis. Thus, there is apparently a pathway of astrocyte destruction in NMO lesions, which is different from complement and granulocyte mediated lysis. Interestingly, this disturbance and loss of astrocyte was not necessarily associated with demyelination nor neurodegeneration, which is in line with previous observations [41].

In addition we found lesions (lesion type 6) in NMO patients, characterized by complete demyelination and axonal preservation. Astrocytes within these lesions were present, but some showed changes of clasmatodendrosis, described above. It is likely that in these lesions, as in the destructive complement-mediated lesions, oligodendrocyte injury and demyelination follows astrocyte injury and loss. Interestingly, initial alterations of oligodendrocytes and myelin, consistent of oligodendrocyte apoptosis and loss of distal oligodendrocyte processes, which had originally been defined in a subset of active multiple sclerosis lesions [27], are also seen in actively demyelinating NMO lesions [5]. It has, thus, been suggested that in NMO as well as in MS, demyelination may follow an initial astrocyte injury [38]. Astrocytes are important for creating a homeostatic environment for oligodendrocytes. Energy demand of oligodendrocytes and axons is in part provided by astrocytes, transferring lactate through gap junctions to oligodendrocytes [9]. Loss of gap junction-related connexins that are expressed on astrocytes or oligodendrocytes has been found in active lesions of MS and NMO [34, 49]. In addition, astrocytes express the excitatory amino acid transporter 2 (EAAT2), which removes toxic glutamate from the extracellular space and can, thus, reduce excitotoxic cell death of neurons and oligodendrocytes [30]. Since demyelination in a subset of MS lesions is associated with oxidative damage, mitochondrial injury [29] and a state of virtual hypoxia [1], it could also be that such lesions are induced 
in both conditions by additional hypoxia-like mechanisms. In NMO, severe tissue edema may impair blood microcirculation. In addition, oxidative damage and hypoxia-like tissue injury can be amplified by glutamate toxicity, which is expected to occur in such NMO lesions due to the loss of EAAT2 [13, 30].

Although loss of AQP4 has been described before in actively demyelinating lesions in a subset of MS patients $[32,33,49]$ and was also seen in this study, this was not associated with complement activation, granulocyte infiltration, astrocyte destruction or loss [35, 43] or astrocyte clasmatodendrosis. AQP4 loss in this condition rather reflected retraction of perivascular astrocyte processes, similar to that present in CNS lesions induced by severe innate immunity-driven inflammation [49]. The lack of astrocyte loss or complement deposition does not support the view that antibodies against Kir 4.1, which have recently been described in around $47 \%$ of all MS patients [50], destroy astrocytes in the lesions in a complementdependent manner.

For clinicians in front of NMO patients, these various patterns must be informative. For Type 1 and 2, we should consider the earliest strategy to remove the humoral factors such as immunoglobulin and complement in the acute stage, probably by plasmapheresis [55], and to decrease complement activity possibly by anti-C5 antibodies [40], by preventing granulocyte infiltration [42, 47]. Alternatively, blocking endogenous auto-antibody binding with aquaporumab, which binds to AQP4 but is unable to activate complement or interact with effector cells [53] may be beneficial. Inhibition of complement activation or granulocyte infiltration are promising to at least partially block lesion types $1-3$, and thus to ameliorate acute disease exacerbations. However, it is unlikely that these treatment strategies have a major effect on the lesion types 4-6, and therefore will not fully prevent disease progression. In contrast, persistent reduction of serum auto-antibody titers, for instance by immunosuppressive drugs or antiCD20 antibodies [17], or blockade of AQP4 antibody binding by small molecule inhibitors [54], may be more effective against the entire spectrum of NMO lesions. Finally, the presence of destructive spinal cord lesions and the resulting Wallerian tract degeneration may explain, why in NMO patients, after the improvement of motor functions of transverse myelopathy, spastic paraparesis and pain with severe girdle sensation tend to persist chronically [18]. Finally, our current results provide further evidence that NMO is a disease, which is distinctly different from MS, and that astrocyte injury and destruction is the primary event, which occurs in active lesions. However, the mechanisms of tissue injury are complex and effective neuroprotective therapy may have to target several different mechanisms in parallel.
Acknowledgements The study was funded by the Austrian Science Fund (Project I 916-B13; E-Rare-2 Eugene Devic European Network; HL) and by a Scholarship of the Canon Foundation; TM. We are grateful to K. Okita and Y. Fujiyoshi from Nagoya City University for the contribution of a case of NMO. We are grateful to M. Leiszer, U. Köck and A. Kury for expert technical assistance.

Open Access This article is distributed under the terms of the Creative Commons Attribution License which permits any use, distribution, and reproduction in any medium, provided the original author(s) and the source are credited.

\section{References}

1. Aboul-Enein F, Rauschka H, Kornek B, Stadelmann C, Stefferl A, Brück W, Lucchinetti CF, Schmidbauer M, Jellinger K, Lassmann H (2003) Preferential loss of myelin associated glycoprotein reflects hypoxia-like white matter damage in stroke and inflammatory brain diseases. J Neuropath Exp Neurol 62: $25-33$

2. Bennett JL, Lam C, Kalluri SR, Saijakli P, Bautista K, Dupree C, Glogowska M, Case D, Antel JP, Owens GP, Gilden D, Nessler S, Stadelmann C, Hemmer B (2009) Intrathecal pathogenic antiaquaporin-4 antibodies in early neuromyelitis optica. Ann Neurol 66:617-629

3. Bradl M, Misu T, Takahashi T, Watanabe M, Mader S, Reindl M, Adzemovic M, Bauer J, Berger T, Fujihara K, Itoyama Y, Lassmann H (2009) Neuromyelitis optica: pathogenicity of patient immunoglobulin in vivo. Ann Neurol 66:630-643

4. Brück W, Porada P, Poser S, Riechmann P, Hanefeld F, Kretschmar H-A, Lassmann H (1995) Monocyte/macrophage differentiation in early multiple sclerosis lesions. Ann Neurol. 38:788-796

5. Brück W, Popescu B, Lucchinetti CF, Markovic-Plese S, Gols R, Thal DR, Metz J (2012) Neuromyelitis optica lesions may inform multiple sclerosis heterogeneity debate. Ann Neurol 72: 385-394

6. Devic E (1894) Myélite subaiguë compliquée de névrite optique. Bull Med (Paris) 8:1033-1034

7. Frischer JM, Bramow S, Dal Bianco A, Lucchinetti CF, Rauschka H, Schmidbauer M, Laursen H, Sorensen PS, Lassmann H (2009) The relation between inflammation and neurodegeneration in multiple sclerosis brains. Brain 132:1175-1189

8. Fujihara K, Misu T, Nakashima I, Takahashi T, Bradl M, Lassmann H, Takano R, Nishiyama S, Takai Y, Suzuki C, Sato D, Kuroda H, Nakamura M, Fujimori J, Narikawa K, Sato S, Itoyama Y, Aoki M (2012) Neuromyelitis optica should be classified as an astrocytopathic disease rather than a demyelinating disease. Clin Exp Neuroimmunol 3:58-73

9. Fünfschilling U, Supplie LM, Mahad D, Boretius S, Saab AS, Edgar J, Brinkmann BG, Kassmann CM, Tzyetanova ID, Möbius W, Diaz F, Meier D, Suter U, Hamprecht B, Sereda MW, Moraes CT, Frahm J, Goebbels S, Nave KA (2012) Glycolytic oligodendrocytes maintain myelin and long-term axonal integrity. Nature 485:517-521

10. Gelot A, Vilapol S, Bilette de Vilemeur T, Renolleau S, CharriautMarlangue C (2008) Astrocytic demise in the developing rat and human brain after hypoxic-ischemic damage. Dev Neurosci 31:459-470

11. Hinson SR, McKeon A, Lennon VA (2010) Neurological autoimmunity targeting aquaporin-4. Neuroscience 168:1009-1018

12. Hinson SR, Pittock SJ, Lucchinetti CF, Roemer SF, Fryer JP, Kryzer TJ, Lennon VA (2007) Pathogenic potential of IgG binding to water channel extracellular domain in neuromyelitis optica. Neurology 69:2221-2231 
13. Hinson SR, Roemer SF, Lucchinetti CF, Fryer JP, Kryzer TJ, Chamberlain JL, Howe CL, Pittock SJ, Lennon VA (2008) Aquaporin-4-binding autoantibodies in patients with neuromyelitis optica impair glutamate transport by down-regulating EAAT2. J Exp Med 205:2437-2481

14. Hinson SR, Romero MF, Popescu BF, Luchinetti CF, Fryer JP, Wolburg H, Falier-Becker P, Noell S, Lennon V (2012) Molecular outcomes of neuromyelitis optica (NMO)-IgG binding to aquaporin-4 in astrocytes. Proc Natl Acad Sci (USA) 109:1245-1250

15. Höftberger R, Fink S, Aboul-Enein F, Botond G, Olah J, Berki T, Ovadi J, Lassmann H, Budka H, Kovacs GG (2010) Tubulin polymerization promoting protein (TPPP/p25) as a marker for oligodendroglial changes in multiple sclerosis. Glia 58:1847-1857

16. Hulse RD, Winterfield J, Kunkler PE, Kraig RP (2001) Astrocytic clasmatodendrosis in hippocampal organ culture. Glia 33:169-179

17. Jarius S, Aboul-Enein F, Waters P, Kuenz B, Hauser A, Berger T, Lang W, Reindl M, Vincent A, Kristoferitsch W (2008) Antibody to aquaporin- 4 in the long-term course of neuromyelitis optica. Brain 131:3072-3080

18. Kanamori Y, Nakashima I, Takai Y, Nishiyama S, Kuroda H, Takahashi T, Kanaoka-Suzuki C, Misu T, Fujihara K, Itoyama Y (2011) Pain in neuromyelitis optica and its effect on quality of life: a cross-sectional study. Neurology 77:652-658

19. Kim JE, Ryu HJ, Yeo SI, Kang TC (2011) P2X7 receptor differentially modulates astroglial apoptosis and clasmatodendrosis in rat brain following status epilepticus. Hippocampus 21:1318-1333

20. Kinoshita M, Nakatsuji Y, Moriya M, Okuno T, Kumanogoh A, Nakano M, Takahashi T, Fujihara K, Tanaka K, Sakoda S (2009) Astrocytic necrosis is induced by anti-aquaporin-4 antibody-positive serum. NeuroReport 20:508-512

21. Kutzelnigg A, Lucchinetti CF, Stadelmann C, Brück W, Rauschka H, Bergmann M, Schmidbauer M, Parisi J, Lassmann H (2005) Cortical demyelination and diffuse white matter injury in multiple sclerosis. Brain 128:2705-2712

22. Lassmann H, Brück W, Lucchinetti C (2007) The immunopathology of multiple sclerosis: an overview. Brain Pathol 17:210-218

23. Lassmann $\mathrm{H}$ (2011) The architecture of inflammatory demyelinating lesions: implications for studies on pathogenesis. Neuropath Appl Neurobiol 37:698-710

24. Lehmann GL, Gradilone SA, Marinelli RA (2004) Aquaporin water channels in central nervous system. Curr Neurovsc Res 1:209-303

25. Lennon VA, Kryzer TJ, Pittock SJ, Verkman AS, Hinson SR (2005) IgG marker of optic-spinal multiple sclerosis binds to the aquaporin-4 water channel. J Exp Med 202:473-477

26. Lennon VA, Wingerchuk DM, Kryzer TJ, Pittock SJ, Lucchinetti CF, Fujihara K, Nakashima I, Weinshenker BG (2004) A serum autoantibody marker of neuromyelitis optica: distinction from multiple sclerosis. Lancet 364:2106-2112

27. Lucchinetti C, Brück W, Parisi J, Scheithauer B, Rodriguez M, Lassmann H (2000) Heterogeneity of multiple sclerosis lesions: implications for the pathogenesis of demyelination. Ann Neurol 47:707-717

28. Lucchinetti CF, Mandler R, McGavern D, Brück W, Gleich G, Ransohoff RM, Trebst C, Weinshenker B, Wingerchuck D, Parisi J, Lassmann H (2002) A role for humoral mechanisms in the pathogenesis of Devic's neuromyelitis optica. Brain 125:1450-1461

29. Mahad D, Ziabreva I, Lassmann H, Turnbull D (2008) Mitochondrial defects in acute multiple sclerosis lesions. Brain 131:1722-1735

30. Marignier R, Nicolle A, Watrin C, Touret M, Cavagna S, Varrin-Doyer M, Cavillon G, Rogemond V, Confavreux C, Honnorat J, Giraudon P (2010) Oligodendrocytes are damaged by neuromyelitis optica immunoglobulin $G$ via astrocyte injury. Brain 133:2578-2591

31. Matsuoka T, Matsushita T, Kawano Y, Osoegawa M, Ochi H, Ishizu T, Minohara M, Kikuchi H, Mihara F, Ohyagi Y, Kira J (2007) Heterogeneity of aquaporin-4 autoimmunity and spinal cord lesions in multiple sclerosis in Japanese. Brain 130:1206-1223

32. Matsuoka T, Suzuki SO, Iwaki T, Tabira T, Ordinario AT, Kira J (2010) Aquaporin-4 astrocytopathy in Balo's disease. Acta Neuropathol 120:651-680

33. Matsuoka T, Suzuki SO, Suenaga T, Iwaki T, Kira J (2011) Reappraisal of aquaporin-4 astrocytopathy in asian neuromyelitis optica and multiple sclerosis patients. Brain Pathol 21:516-532

34. Matsushita T, Masaki K, Suzuki S, Matsuoka T, Yonekawa T, Wu XM, Tabira T, Iwaki T, Kira J (2011) Astrocytopathy in neuromyelitis optica, multiple sclerosis and Balo's disease. Rinsho Shinkeigaku 51:898-900

35. Misu T, Fujihara K, Kakita A, Konno H, Nakamura M, Watanabe S, Takahashi T, Nakashima I, Takahashi H, Itoyama Y (2007) Loss of aquaporin 4 in lesions of neuromyelitis optica: distinction from multiple sclerosis. Brain 130:1224-1234

36. Misu T, Fujihara K, Nakamura M, Murakami K, Endo M, Konno $\mathrm{H}$, Itoyama Y (2006) Loss of aquaporin-4 in active perivascular lesions in neuromyelitis optica: a case report. Tohoku J Exp Med 209:269-275

37. Misu T, Takano R, Fujihara K, Takahashi T, Sato S, Itoyama Y (2009) Marked increase in cerebrospinal fluid glial fibrillar acidic protein in neuromyelitis optica: an astrocytic damage marker. J Neurol Neurosurg Psychiatry 80:575-577

38. Parratt JD, Prineas JW (2010) Neuromyelitis optica: a demyelinating disease characterized by acute destruction and regeneration of perivascular astrocytes. Mult Scler 16:1156-1172

39. Piddlesden SJ, Lassmann H, Zimprich F, Morgan BP, Linington C (1993) The demyelinating potential of antibodies to myelin oligodendrocyte glycoprotein is related to their ability to fix complement. Am J Pathol 143:555-564

40. Pittock SJ, McKeon A, Mandrekar JN, Weinshenker BG, Lucchinetti CF, Wingerchuk DM (2012) Pilot clinical trial of eculizumab in AQP4-Ig-G-positive NMO. In: Presented at the 2012 annual meeting of the American Neurological Association, Boston, MA, October 9, 2012 (Abstract T1826)

41. Popescu BF, Parisi JE, Cabrera-Gomez JA, Newell K, Mandler RN, Pittock SJ, Lennon VA, Weinshenker BG, Lucchinetti CF (2012) Absence of cortical demyelination in neuromyelitis optica. Neurology 75:2103-2109

42. Ratelade J, Verkman AS (2012) Neuromyelitis optica: aquaporin- 4 based pathogenesis mechanisms and new therapies. Int $\mathrm{J}$ Biochem Cell Biol 44:1519-1530

43. Roemer SF, Parisi JE, Lennon VA, Benarroch EE, Lassmann H, Bruck W, Mandler RN, Weinshenker BG, Pittock SJ, Wingerchuk DM, Lucchinetti CF (2007) Pattern-specific loss of aquaporin-4 immunoreactivity distinguishes neuromyelitis optica from multiple sclerosis. Brain 130:1194-1205

44. Rossi A, Ratelade J, Papadopoulos MC, Bennett JL, Verkman AS (2012) Neuromyelitis optica IgG does not alter aquaporin-4 water permeability, plasma membrane M1/M23 isoform content, or supramolecular assembly. Glia 60:2027-2039

45. Ryu HJ, Kim JE, Yeo SI, Kim DW, Kwon CS, Choi SY, Kang TC (2011) F-actin depolymerization accelerates clasmatodendrosis via activation of lysosomes-derived autophagic astroglial death. Brain Res Bull 85:368-373

46. Saadoun S, Waters P, Bell BA, Vincent A, Verkman AS, Papadopoulos MC (2010) Intra-cerebral injection of neuromyelitis optica immunoglobulin $\mathrm{G}$ and human complement produces neuromyelitis optica lesions in mice. Brain 133:349-361 
47. Saadoun S, Waters P, MacDonald C, Bell BA, Vincent A, Verkman AS, Papadopoulos MC (2012) Neutrophil protease inhibition reduces neuromyelitis optica-immunoglobulin G-induced damage in mouse brain. Ann Neurol 71:323-333

48. Satoh J, Tabunoki H, Yamamura T, Arima K, Konno H (2007) Human astrocytes express aquaporin-1 and aquaporin-4 in vitro and in vivo. Neuropathology 27:245-256

49. Sharma R, Fischer MT, Bauer J, Felts PA, Smith KJ, Misu T, Fujihara K, Bradl M, Lassmann H (2010) Inflammation induced by innate immunity in the central nervous system leads to primary astrocyte dysfunction followed by demyelination. Acta Neuropathol 120:223-236

50. Srivastava R, Aslam M, Kalluri SR, Schirmer L, Buck D, Tackenberg B, Rothhammer V, Chan A, Gold R, Berthele A, Bennet JL, Korn T, Hemmer B (2012) Potassium channel KIR4.1 as an immune target in multiple sclerosis. New Engl J Med 367:115-123

51. Takano R, Misu T, Takahashi T, Sato S, Fujihara K, Itoyama Y (2010) Astrocytic damage is far more severe than demyelination in NMO: a clinical CSF biomarker study. Neurology 75:208-216
52. Tomimoto H, Akiguchi I, Wakita H, Suenaga T, Nakamura S, Kimura J (1997) Regressive changes of astroglia in white matter lesions in cerebrovascular disease and Alzheimer's disease patients. Acta Neuropathol 94:146-152

53. Tradtrantip L, Zhang H, Saadoun S, Phuan PW, Lam C, Papadopoulos MC, Bennett JL, Verkman AS (2012) Anti-aquaporin-4 monoclonal antibody blocker therapy for neuromyelitis optica. Ann Neurol 71:314-322

54. Tradtrantip L, Zhang H, Anderson MO, Saadoun S, Phuan PW, Papadopoulos MC, Bennett JL, Verkman AS (2012) Small molecule inhibitors of NMO-IgG binding to aquaporin-4 reduce astrocyte cytotoxicity in neuromyelitis optica. FASEB J 26:2197-2208

55. Watanabe S, Nakashima I, Misu T, Miyazawa I, Shiga Y, Fujihara K, Itoyama Y (2007) Therapeutic efficacy of plasma exchange in NMO-IgG-positive patients with neuromyelitis optica. Mult Scler 13:128-132

56. Wingerchuck DM, Lennon VA, Pittock SJ, Luchinetti CF, Weinshenker BG (2006) Revised diagnostic criteria for neuromyelitis optica. Neurology 66:1485-1489 